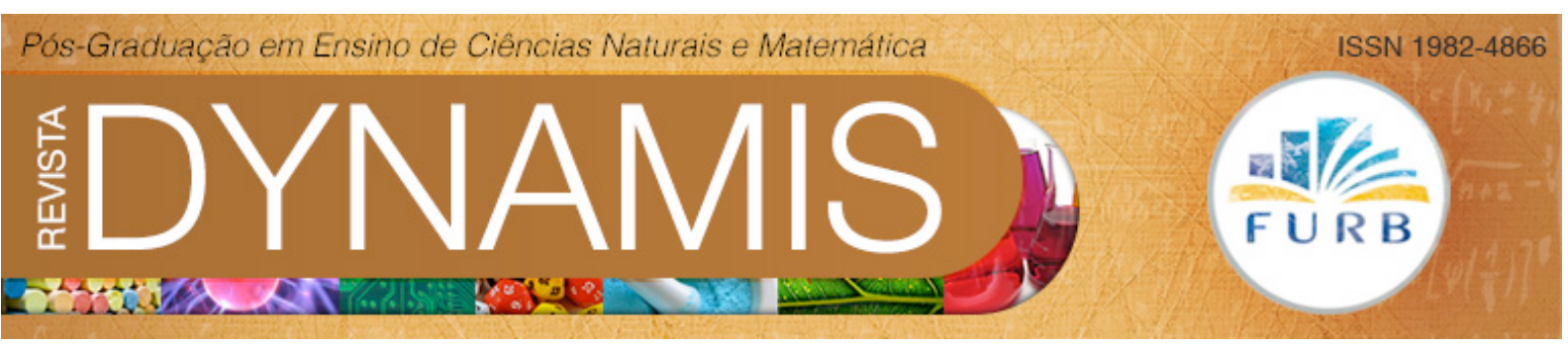

\title{
Cursos de Graduação em Ciências: uma Análise dos Dados do Exame Nacional de Desempenho dos Estudantes - ENADE
}

Science Undergraduate Courses: an Analysis of Data from the National Survey of Student Performance - ENADE

Rossano André Dal-Farra

Programa de Pós-Graduação em Ensino de Ciências e Matemática da Universidade Luterana do Brasil Av. Farroupilha, n. 8001, Bairro São José, CEP 92425900. Canoas/RS.

rossanodf@uol.com.br

\section{Maria Eloisa Farias}

Programa de Pós-Graduação em Ensino de Ciências e Matemática da Universidade Luterana do Brasil Av. Farroupilha, n. 8001, Bairro São José, CEP 92425900. Canoas/RS

mariefs10@yahoo.com.br

Marlise Geller

Programa de Pós-Graduação em Ensino de Ciências e Matemática da Universidade Luterana do Brasil Av. Farroupilha, n. 8001, Bairro São José, CEP 92425900. Canoas/RS

marlise.geller@gmail.com

Paulo Tadeu Campos Lopes

Programa de Pós-Graduação em Ensino de Ciências e Matemática da Universidade Luterana do Brasil Av. Farroupilha, n. 8001, Bairro São José, CEP 92425900. Canoas/RS

ptclopes@gmail.com

Tânia Renata Prochnow

Programa de Pós-Graduação em Ensino de Ciências e Matemática da Universidade Luterana do Brasil Av. Farroupilha, n. 8001, Bairro São José, CEP 92425900. Canoas/RS

taniapro@gmail.com

Artigo recebido em 08/08/2012. Avaliado por pares e publicado em 22/12/2012. 


\section{Resumo}

Os desafios da docência contemporânea no Ensino de Ciências têm demandando uma sólida formação no âmbito técnico, nas questões relativas à docência e nos grandes temas da contemporaneidade atinentes à denominada formação geral. Diante do aumento do número de cursos e das modificações na legislação educacional pelo SINAES e pelas Diretrizes Curriculares Nacionais para a formação de professores não podemos prescindir de estudos que analisem os indicadores produzidos nos últimos anos, visando compreender melhor as questões relevantes na formação dos docentes para a Educação em Ciências no Brasil. Por esta razão, o objetivo deste estudo é avaliar os dados oriundos do Exame Nacional de Desempenho dos Estudantes do ano de 2008 analisando os resultados obtidos pelos alunos de Química, Física e Biologia, comparando-os com estudantes de cursos da área de Ciências Humanas, visando contribuir para o importante repensar das práticas educativas nos cursos de formação de professores.

Palavras-chave: Educação superior, ENADE, ensino de ciências, formação de professores.

\section{Abstract}

The challenges of teaching science in contemporary education became necessary a consistent knowledge including specific contents and social relevant issues pertaining to general education. Considering the increasing of undergraduate courses and the changes in educational laws brought by SINAES and National Curriculum Guidelines related to teacher's education, we have news indicators to analyze aiming to understand the relevant subjects related to science education in Brazil. Based on these premises, the objective of this study is to evaluate the data of ENADE of 2008 mainly the results obtained by students of Chemistry, Physics and Biology comparing with humanities courses, aiming to construct subsidies to the necessary reflections about educational practices in teacher education.

Keywords: Higher education, ENADE, science education, teacher education. 


\section{Introdução}

A crescente inserção da Ciência e da Tecnologia na vida cotidiana e as preocupações com o impacto provocado no ambiente natural demandam crescentes desafios para os professores que atuam no Ensino de Ciências. Neste cenário se torna necessário o desenvolvimento de uma sólida formação, tanto no âmbito técnico, quanto nas questões relativas à docência e aos grandes temas da contemporaneidade relacionados à formação geral.

O pronunciado aumento no número de cursos e as modificações na legislação decorrentes do Sistema Nacional de Avaliação da Educação Superior e da publicação das Diretrizes Curriculares Nacionais para a formação de professores se traduzem em novos desafios para o constante repensar da formação de professores no Brasil, buscando contribuir para o fortalecimento da cidadania nos âmbitos técnico-científicos e sociais. Para Pimenta e Ghedin (2005) a concretização deste processo está centrada em três fatores principais: um currículo fortemente articulado para dar conta de sua aplicação; um local para o exercício dessa formação e, sobretudo, condições concretas para o exercício de uma prática profissional reflexiva.

Considerando a carência de pesquisas abrangentes que indiquem caminhos relevantes para a formação de professores de ciências, o presente estudo avalia os dados oriundos do Exame Nacional de Desempenho dos Estudantes (ENADE) do ano de 2008, comparando-os com os dados de 2005 visando estimular reflexões a respeito da articulação entre as questões específicas e a formação geral. Para esta finalidade foram avaliados os resultados obtidos pelos alunos dos cursos de Química, Física e Biologia, cotejando-os com dados de cursos das Ciências Humanas constantes nos relatórios publicados pelo Ministério da Educação. Tais informações se constituem em importantes referências para o conhecimento do contexto institucional e para a permanente busca da melhoria da qualidade da graduação, aspectos que ratificam o caráter integrativo inerente ao constante repensar das práticas realizadas na educação, mormente no caso da formação de professores.

\section{Sistema Nacional de Avaliação do Ensino Superior}

No ano de 2004, a Lei 10.861 instituiu o Sistema Nacional de Avaliação da Educação Superior - SINAES destinado à realização de um Processo Nacional de Avaliação das Instituições de Ensino Superior segundo orientações da LDB 9394/96, incluindo as condições de oferta dos Cursos de Graduação e o desempenho acadêmico de seus estudantes. O SINAES envolve: a auto-avaliação pela Comissão Própria de Avaliação (CPA) nas próprias instituições; a avaliação externa realizada por comissões de especialistas; o ENADE - Exame Nacional de Desempenho dos Estudantes; o Censo da Educação Superior e o Cadastro de Cursos e Instituições.

A análise dos dados obtidos com o SINAES possibilita a construção de balizadores para a orientação de políticas públicas, assim como o acompanhamento contínuo das atividades dos cursos. A partir de 2008 foi incluído também o Conceito Preliminar de Curso (CPC) que engloba os resultados obtidos pelos estudantes no ENADE e as informações fornecidas pelos estudantes pelo preenchimento do Questionário Sócio-Econômico. O CPC é utilizado para subsidiar a renovação de reconhecimento dos cursos de graduação.

O objetivo do ENADE é o acompanhamento do processo de aprendizagem utilizando como indicador o desempenho dos estudantes em relação aos conteúdos programáticos previstos nas diretrizes curriculares de cada curso, incluindo a compreensão dos "temas exteriores ao âmbito específico de sua profissão", relacionados ao contexto brasileiro e 
mundial $^{1}$. No ano de 2008 foram inscritos como ingressantes os estudantes que haviam concluído entre 7 e $22 \%$ do currículo do curso até o dia 01 de agosto daquele ano e como concluintes os que haviam cumprido pelo menos $80 \%$ da carga horária ou estivessem concluindo o curso naquele ano. Uma parcela dos inscritos foi selecionada aleatoriamente para a realização do exame (BRASIL, 2008a).

O ENADE contextualiza as temáticas abordadas no ensino superior, relacionando-as com os temas relevantes no âmbito laboral e social, assim como busca a compreensão dos aspectos culturais, sociais e políticos no âmbito local e global (BOPP e DAL-FARRA, 2011). A prova é composta por dez questões relacionadas à formação geral (Tabela 1) e trinta questões relacionadas à formação específica.

Tabela 1 - Aspectos fundamentais do componente de Formação Geral (BRASIL, 2008b)

\begin{tabular}{l|l}
\hline Temas & $\begin{array}{l}\text { sociodiversidade, exclusão e minorias, biodiversidade, ecologia, mapas sócio e geopolítico, } \\
\text { globalização, arte, cultura e filosofia, políticas públicas para educação, saúde e outros }\end{array}$ \\
& $\begin{array}{l}\text { aspectos, redes sociais e responsabilidade, relações interpessoais, vida urbana e rural, } \\
\text { inclusão digital, democracia e cidadania, violência, terrorismo, avanços tecnológicos, } \\
\text { relações de trabalho, tecnociência, propriedade intelectual e diferentes mídias e tratamento } \\
\text { da informação }\end{array}$ \\
\hline $\begin{array}{l}\text { Capacidades } \\
\text { verificadas }\end{array}$ & $\begin{array}{l}\text { ler e interpretar textos, analisar e criticar informações, extrair conclusões por indução e/ou } \\
\text { dedução, estabelecer relações, comparações e contrastes em diferentes situações, detectar } \\
\text { contradições, fazer escolhas valorativas avaliando conseqüências, questionar a realidade e } \\
\text { argumentar coerentemente. }\end{array}$ \\
\hline $\begin{array}{l}\text { Competências } \\
\text { envolvidas }\end{array}$ & $\begin{array}{l}\text { projetar ações de intervenção, propor soluções para situações-problema; construir } \\
\text { perspectivas integradoras; elaborar sínteses; administrar conflitos. }\end{array}$ \\
\hline
\end{tabular}

Verifica-se nos aspectos arrolados um processo de inserção dos grandes temas da contemporaneidade para a análise contextualizada por parte dos estudantes, assim como a compreensão de dados com base nos princípios da estatística. Examinando as questões de Estatística inseridas no ENADE do ano de 2004 realizado por cursos da Área da Saúde e Agrárias, Vendramini et al. (2010) afirmam que as mesmas apresentavam um elevado grau de dificuldade, necessitando o desenvolvimento de habilidades para conseguir responder adequadamente o que era solicitado. Os resultados apontaram a presença de importantes diferenças entre os cursos no desempenho dos estudantes em questões relevantes para a formação profissional nos diferentes campos do conhecimento.

\section{Formação de professores para o ensino de ciências}

Segundo Relatório do Ministério da Educação publicado em 2009, o Brasil contava com quase dois milhões de professores atuando na Educação Básica (1.977.978) sendo 67,8\% deste possuindo curso superior. Do total de graduados 95,3\% eram licenciados. Estes docentes atuavam em um universo composto por mais de 52 milhões de alunos (52.580.452), sendo quase 32 milhões no Ensino Fundamental (31.705.528) e mais de 8 milhões no Ensino Médio (8.337.160), além de outros na modalidade de Educação de Jovens e Adultos e na Educação Profissional (Brasil, 2009b; 2009c).

Conforme o Censo da Educação Superior do Brasil em 2008 havia 7.247 cursos presenciais, somando licenciatura e licenciatura/bacharelado no Brasil, correspondendo a $30,1 \%$ do total de cursos no país. Na Educação a Distância havia 347 cursos. Naquele ano

\footnotetext{
${ }^{1} \mathrm{http} / /$ www.inep.gov.br/superior/enade/notas_tecnicas.htm
} 
foram contabilizadas 1.147.899 matrículas presenciais e na Educação a Distância foram 344.875 matrículas. O mesmo censo apontou que $17,6 \%$ das matrículas estavam em cursos de licenciatura e licenciatura/bacharelado, sendo na Educação a Distância 47,4\% das matrículas (BRASIL, 2009a). Embora muitos cursos tenham sido criados nos últimos anos, este aumento não foi acompanhado pelo equivalente número de matrículas, havendo um número expressivo de vagas ociosas.

Outro aspecto importante se refere ao desinteresse dos alunos em ocupar as vagas da docência. Há uma tendência dos estudantes preferirem as questões específicas da sua área e não as questões mais atinentes à formação docente, contribuindo para a construção de barreiras de resistência na adoção de medidas de caráter interdisciplinar no âmbito do currículo dos cursos de ciências (GATTI e BARRETO, 2009).

Observa-se que as construções curriculares refletem preponderantemente os aspectos que fazem sentido a cada cultura, a cada país e a cada região que as elaboram. Assim, ao longo do tempo o Ensino de Ciências tem sido acompanhado de tendências distintas em um processo dialógico com os demais campos do saber e os demais âmbitos da organização social. Segundo Krasilchik e Marandino $(2004$, p. 5) os projetos visando à transformação do ensino de ciências foram, ao longo do tempo, inserindo elementos que refletem as alterações resultantes dos âmbitos políticos e econômicos que se constituem em "vasos comunicantes entre as disciplinas tradicionais de Física, Química e Biologia e destas com Filosofia, História, Geografia e Arte, entre outras".

A partir da década de 90 foi observado o desenvolvimento de grupos de pesquisa englobando o Ensino de Ciências e Matemática. Em setembro de 2000 foi criada a Área de Ensino de Ciências e Matemática pela CAPES (Área 46), sendo que desde 1997 há encontros nacionais bianuais de Ensino de Ciências, assim como inúmeros eventos na área de Matemática, Física, Química e Biologia (MOREIRA, 2002). Entre os processos de desenvolvimento de conhecimento desta área incluem-se a tendência de inserir a ciência e a tecnologia na saúde e na qualidade de vida das pessoas, buscando um olhar interdisciplinar que possa contribuir para o cidadão e para a sua inserção no cotidiano da sociedade. Deste modo se torna imprescindível a contextualização da pesquisa científica em relação às consequências sociais, políticas e culturais (KRASILCHIK e MARANDINO, 2004).

Nessa perspectiva, a análise de dados do ENADE contribui para que sejam verificados alguns indicadores da contextualização do conhecimento mais estritamente técnico no decorrer da formação dos estudantes nos cursos de graduação, principalmente pelo fato de todos responderem as questões de Formação Geral.

\section{Metodologia}

Foram analisados dados do ENADE e do Cadastro Docente (BRASIL, 2012b), assim como as respostas obtidas com os questionários preenchidos pelos estudantes em relação à infraestrutura, à organização didático-pedagógica e aos dados da titulação e regime de trabalho docente. Ressalta-se que as informações constantes no relatório e utilizadas neste estudo apresentam conjuntamente os dados de Licenciatura e Bacharelado de cada instituição que realizou o processo avaliativo, não havendo distinção entre as informações pertencentes a uma ou outra formação. O referido arquivo fornece informações valiosas no sentido de compreender as condições de oferta dos cursos, assim como possibilita a análise de indicadores relevantes para a formação de professores como pode ser visualizado na Tabela 2. 
Tabela 2 - Dados do Relatório do Conceito Preliminar de Curso de 2008

Variável no relatório

Comentário

\begin{tabular}{|c|c|}
\hline \multicolumn{2}{|r|}{ Biologia, Física, Geografia, História, Matemática, Pedagogia ou Química } \\
\hline Dep. administrativa & Federal, estadual, municipal ou privada \\
\hline $\mathrm{N}$ ingressantes & Número de ingressantes que realizaram o exame \\
\hline $\mathrm{N}$ concluintes & Número de concluintes que realizaram o exame \\
\hline Média FG_Ing & Média obtida pelos ingressantes de cada curso na Formação Geral \\
\hline Média FG_Conc & Média obtida pelos concluintes de cada curso na Formação Geral \\
\hline Média CE_Ing & Média obtida pelos ingressantes de cada curso na Formação Específica \\
\hline Média CE_Conc & Média obtida pelos concluintes de cada curso na Formação Específica \\
\hline $\begin{array}{l}\text { \%equipdispsãosufic (resp. } \\
\text { A/B) }\end{array}$ & $\begin{array}{l}\text { Aulas práticas: Os equipamentos disponíveis são suficientes para o número de } \\
\text { estudantes? }\end{array}$ \\
\hline & A) Sim, em todas elas. \\
\hline & B) Sim, na maior parte delas. \\
\hline & C) Sim, mas apenas na metade delas. \\
\hline & D) Sim, mas em menos da metade delas. \\
\hline & E) Não, em nenhuma. \\
\hline & O percentual apresentado no arquivo é a soma das respostas A e B. \\
\hline \%avalbemplanoensino(res & "Os planos de ensino contêm todos os seguintes aspectos: objetivos; procedimentos \\
\hline A) & de ensino e avaliação; conteúdos e bibliografia da disciplina?”. \\
\hline & A) Sim, todos contêm. \\
\hline & B) Sim, a maior parte contém. \\
\hline & C) Sim, mas apenas cerca da metade contém. \\
\hline & D) Sim, mas apenas menos da metade contém. \\
\hline & E) Não, nenhum contém. \\
\hline & O percentual apresentado no arquivo é apenas o das respostas A. \\
\hline$\%$ Mestres & \% de professores vinculados ao curso com titulação é maior ou igual ao mestrado. \\
\hline$\%$ Doutores & \% de professores vinculados ao curso com titulação maior ou igual ao doutorado. \\
\hline $\begin{array}{l}\text { \%Docentes } \\
\text { Par/Int }\end{array}$ & $\%$ de professores vinculados ao curso com regime de dedicação integral ou parcial \\
\hline
\end{tabular}

$\mathrm{Na}$ tabulação dos dados foi calculada a média ponderada do desempenho de ingressantes e concluintes para Formação Geral (FG) e para a Formação Específica (FE) conforme exemplificado pelo cálculo da média da Formação Geral para os ingressantes do curso de Física:

$$
\text { FFGI } \left.=\sum_{i=1}^{n} \overline{\mathrm{X}}_{i} \mathrm{X} \mathrm{n}_{i}\right) / \mathrm{y}
$$

Onde:

$$
\begin{aligned}
& \text { FFGI = desempenho dos ingressantes do curso de Física na formação geral } \\
& \sum_{n}=\text { somatório } \\
& \overline{\mathrm{X}}_{i}=\text { média da Formação Geral dos ingressantes do curso } i \text { de Física } \\
& \mathrm{n}_{i}=\text { número de ingressantes do curso } i \text { de Física } \\
& \text { y }=\text { número total de ingressantes que realizaram o exame no curso de Física. }
\end{aligned}
$$

Posteriormente foi obtida a diferença entre os desempenhos dos concluintes e dos ingressantes em cada curso, tanto na FG, quanto na FE, assim como foi calculado o percentual 
de aumento ocorrido dos ingressantes e dos concluintes em cada curso. Este percentual foi calculado dividindo o valor obtido pela diferença entre concluintes e ingressantes pelo desempenho dos ingressantes multiplicado por 100, tal como demonstrado para a FG no curso de Biologia:

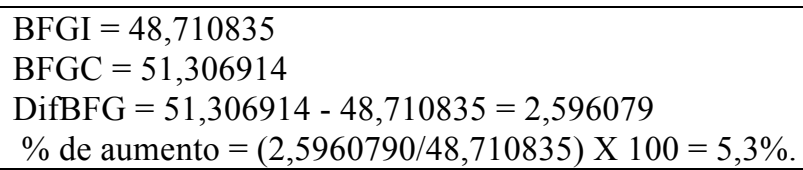

Em relação aos equipamentos e aos planos de ensino foram incluídos apenas os dados de cursos nos quais havia um mínimo de 20 estudantes realizando o exame. Estes dados foram divididos em cinco intervalos, contendo percentuais de 0 a $20 \%$; 20,1 a $40 \%$; 40,1 a 60\%; 60,1 a $80 \%$ e 80,1 a $100 \%$, respectivamente. Com relação à titulação e ao regime de trabalho foram incluídos todos os cursos do relatório, com as informações relacionadas a cada uma destas variáveis divididas nos cinco intervalos mencionados acima. Para fins de análise foram considerados os dados a partir de $60,1 \%$, ou seja, os valores dos dois últimos intervalos foram somados e comparados, curso a curso, por meio das ferramentas da Estatística Descritiva, sendo discutidos segundo as peculiaridades envolvidas em cada conjunto de informações gerado pelos registros do relatório e pelas questões da legislação educacional brasileira.

\section{Resultados e Discussão}

No ano de 2008, a FG do ENADE incluiu questões que procuravam articular as representações culturais com a discussão de temas relevantes da contemporaneidade, predominando as seguintes temáticas: biodiversidade, ecologia, mapas sócio e geopolíticos, arte, cultura e filosofia, saúde, avanços tecnológicos, tecnociência e tratamento da informação. A Tabela 3 apresenta uma análise sucinta das oito questões de múltipla escolha que compunham a prova do referido ano.

Tabela 3 - Descrição sucinta das questões de Formação Geral do ENADE de 2008

\begin{tabular}{cl}
\hline Questão & \multicolumn{1}{c}{ Abordagem e temática } \\
\hline 1 & $\begin{array}{l}\text { Literatura e História Brasileira com imagens de representantes da História Nacional. } \\
\text { Temática ambiental articulando Arte e Ciência, mais precisamente a intervenção do ser humano na } \\
\text { natureza. }\end{array}$ \\
3 & $\begin{array}{l}\text { Análise de dados numéricos envolvendo a questão dos raios ultravioleta e a utilização de protetores } \\
\text { solares. }\end{array}$ \\
4 & $\begin{array}{l}\text { Legislação relacionada aos direitos das mulheres em um contexto social. } \\
\text { Interpretação de imagem histórica relacionada com desemprego na crise de } 1929 .\end{array}$ \\
6 & $\begin{array}{l}\text { Análise de dados apresentados em um mapa relacionado com a organização da sociedade e a questão } \\
\text { geopolítica em relação à utilização da energia na Europa visando redução dos desperdícios. }\end{array}$ \\
7 & $\begin{array}{l}\text { Análise de gráfico com dados de renda no Brasil. } \\
\text { Análise de pinturas articulando Arte e Filosofia. }\end{array}$ \\
\hline
\end{tabular}

Com relação às questões discursivas, uma se referia aos Direitos Humanos envolvendo a habitação, a segurança e o trabalho. A outra solicitava a construção de um texto argumentativo que analisasse dados contraditórios da educação brasileira, mais especificamente a opinião positiva manifestada por alunos que realizaram o ENEM contrastando com os resultados de exames padronizados dos estudantes brasileiros, como o PISA (Programme for International Student Assessment). 
É notória a tentativa de articular temáticas oriundas das Ciências Humanas com questões sociais relevantes expressadas com base na arte pictórica, cujas imagens situam os estudantes em períodos históricos específicos e remetem para a necessidade de contextualizar o conhecimento oriundo de diferentes áreas do saber. Esta é uma tendência que permeia a construção das questões do ENADE, proporcionando a reflexão quanto à pertinência destes aspectos para os cursos de ciências.

Os resultados do ano de 2008 referentes aos cursos relacionados à formação de professores encontram-se na Tabela 4.

Tabela 4 - Médias gerais em cada curso na Formação Geral do ENADE de 2008

\begin{tabular}{llcc}
\multicolumn{1}{c}{ Curso } & Sigla & No. Alunos & Médias \\
\hline Matemática - Formação Geral - Iniciantes & MFGI & 9590 & 46,493756 \\
Matemática - Formação Geral - Concluintes & MFGC & 10347 & 48,320528 \\
Letras - Formação Geral - Iniciantes & LFGI & 17866 & 49,268878 \\
Letras - Formação Geral - Concluintes & LFGC & 22752 & 51,549891 \\
Física Formação Geral - Iniciantes & FFGI & 3137 & 46,335558 \\
Física Formação Geral - Concluintes & FFGC & 2343 & 49,298661 \\
Química Formação Geral - Iniciantes & QFGI & 6719 & 48,935354 \\
Química Formação Geral - Concluintes & QFGC & 5349 & 50,815420 \\
Biologia Formação Geral - Iniciantes & BFGI & 15609 & 48,710835 \\
Biologia Formação Geral - Concluintes & BFGC & 14980 & 51,306914 \\
Pedagogia - Formação Geral - Iniciantes & PFGI & 37473 & 46,326590 \\
Pedagogia - Formação Geral - Concluintes & PFGC & 39949 & 48,581801 \\
História - Formação Geral - Iniciantes & HFGI & 9220 & 47,089263 \\
História - Formação Geral - Concluintes & HFGC & 10529 & 49,354868 \\
Geografia - Formação Geral - Iniciantes & GFGI & 6075 & 47,824657 \\
Geografia - Formação Geral - Concluintes & GFGC & 8179 & 49,300988 \\
\hline
\end{tabular}

Pode ser verificado que os cursos de Letras, Química e Biologia apresentaram os maiores índices de acerto na FG, tanto nos ingressantes, quanto nos concluintes, havendo uma pequena inversão de classificação entre a Biologia e a Química. Verifica-se ainda, que o curso de Física ocupou uma posição intermediária nos concluintes, o que não havia ocorrido entre os ingressantes. Conforme Brito (2007) embora o componente de formação geral do exame não possua questões diretamente vinculadas às disciplinas específicas, espera-se que atualmente os docentes de todos os níveis de ensino agreguem aos conteúdos específicos os aspectos relacionados às questões sociais, políticas e culturais do mundo atual.

Chama a atenção o fato de, à exceção do curso de Letras, cursos como Pedagogia e História não terem apresentado desempenho elevado nos concluintes, permanecendo em posição semelhante ao observado nos ingressantes, o que pode ser explicado, provavelmente, pela presença de diferenças entre o instrumento de avaliação utilizado pelo ENADE e os processos avaliativos empregados no âmbito destes cursos de graduação.

No ENADE, atendendo-se ao princípio de verificar a qualidade do ensino superior, fazse um traçado do perfil dos estudantes de graduação do Brasil, comparando vários cursos quanto ao desempenho dos estudantes na formação geral da prova (BRITO, 2007). É evidente que o exame não é um fim em si mesmo pelas próprias limitações de sua natureza, por isso, nas análises de seus resultados, ele deve ganhar peso como um elemento adicional no contexto dos cursos (SOUSA, 2011).

Os resultados do ENADE de 2005 indicaram que os estudantes de Física apresentaram médias elevadas na Formação Geral quando comparados com os demais cursos incluídos 10 
neste estudo, tanto nos ingressantes (terceira maior média) quanto nos concluintes (segunda maior média), diferentemente do que ocorreu em 2008. No curso de Química ocorreu o inverso, já que as médias foram muito baixas em 2005, ficando abaixo de Geografia, Letras, Física, História, Biologia e Matemática, tanto nos ingressantes, quanto nos concluintes. Em 2008 os valores foram elevados quando comparados aos demais cursos. Este crescimento ocorreu também na Biologia, que havia ocupado a quinta maior média nos ingressantes e a quarta maior média entre os concluintes em 2005 e valores mais elevados em 2008.

A continuidade das análises pode demonstrar tendências mais precisas no desempenho dos estudantes na FG. Percebe-se, entretanto, que o curso de Letras se manteve em posições elevadas, tanto em 2005, quanto em 2008. É possível atribuir aos alunos deste curso um hábito mais pronunciado de leitura, elevando o índice de acertos na FG, principalmente pelo fato da literatura ser um componente importante do exame. Dados dos Relatórios Síntese de 2005 corroboram esta afirmação, pois entre os estudantes de Letras 32,2\% dos ingressantes e $39,3 \%$ dos concluintes leram pelo menos 6 livros. No curso de Geografia $18,6 \%$ dos ingressantes e $23,6 \%$ dos concluintes; no curso de Biologia $14,4 \%$ dos ingressantes e $15,9 \%$ dos concluintes e no curso de Física 17,8\% dos ingressantes e 19,5\% para concluintes. Os tipos de livros mais lidos entre os concluintes foram: livros técnicos nos cursos de Física $(40,7 \%)$, Biologia $(29,4 \%)$ e Geografia $(29,3 \%)$ e obras literárias indicadas com maior frequência pelos estudantes de cursos de Letras (48,3\% ficção e 23,6\% não-ficção) e História (17,7\% ficção e $27,1 \%$ não-ficção). Visando verificar as possíveis mudanças ocorridas ao longo do curso, a Figura 1 apresenta as diferenças entre as médias dos concluintes e dos ingressantes para cada curso em 2008.

Figura 1 - Diferenças entre as médias obtidas pelos concluintes e pelos ingressantes na FG

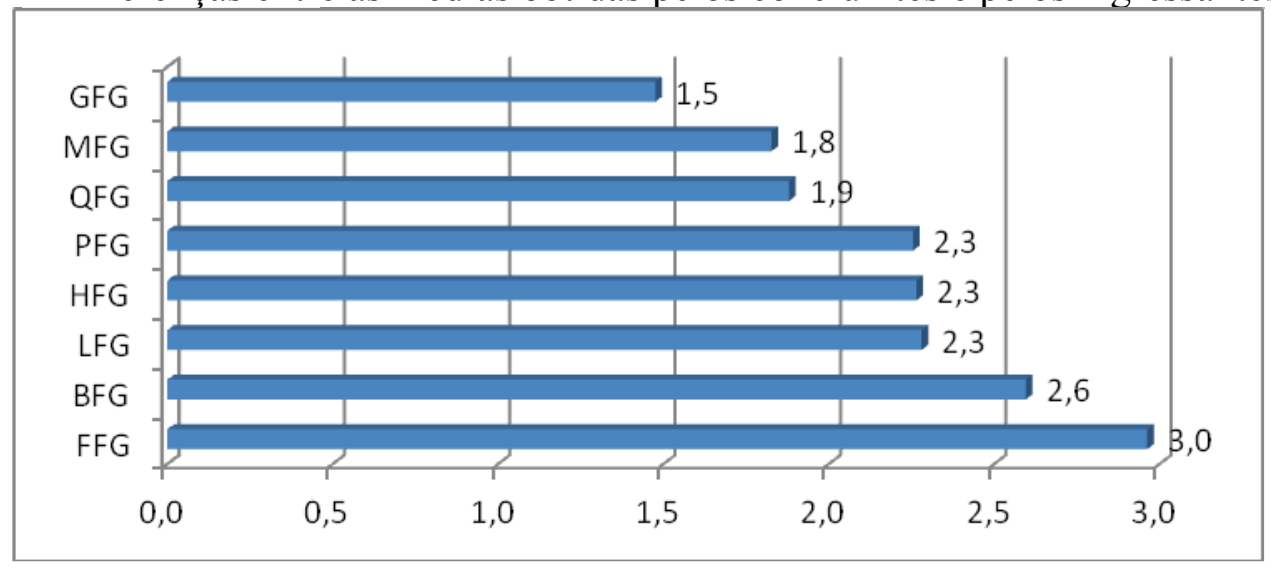

Observando-se a diferença entre as médias de ingressantes e concluintes, na formação geral, verificou-se que houve maior crescimento nos cursos de Física e Biologia, com os cursos de Letras, História e Pedagogia ficando numa posição intermediária.

Para Brito (2007) como a proposta do ENADE é de uma análise de mudança, espera-se que os estudantes que fizeram o exame como ingressantes tenham progredido nos vários itens que compõem a prova, itens estes presentes nas diretrizes curriculares dos diferentes cursos, ocorrendo um incremento significativo nos concluintes.

Os dados constantes nos Relatório Síntese de 2005 indicam que, segundo os concluintes, a principal contribuição do curso havia sido a formação profissional para os estudantes de Biologia, Química e Física, assim como ocorreu para os de Letras, Geografia, 
Pedagogia e Matemática. Entretanto, os percentuais de estudantes que assinalaram "aquisição de cultura/formação geral" foram inferiores nos três cursos de Ciências e em Matemática (entre 8,6 e 17,7\%) comparados aos demais cursos (entre 23,3 e 43,1\%), indicando a tendência de desenvolvimento conceitual com maior profundidade nas temáticas de ordem técnica voltadas para as áreas específicas de formação no Ensino de Ciências.

Buscando compreender a percepção dos estudantes em relação ao "desenvolvimento da sensibilização em relação aos temas socialmente relevantes durante a sua formação", os Relatórios Síntese de 2005 apresentam dados agrupando 11 itens que incluem "habitação, analfabetismo, segurança, exploração do trabalho infantil e/ou adulto, discriminação, desigualdades econômicas e sociais, analfabetismo, entre outros". Os resultados apontam que nos cursos de Ciências e Matemática os valores atribuídos por ingressantes e concluintes foram inferiores (entre 2,1 e 2,5) aos atribuídos pelos estudantes dos demais cursos (entre 2,7 a 3,1 ), considerando que a escala poderia variar entre 0,0 e 4,0 .

\subsection{Formação específica}

A Tabela 5 apresenta os resultados médios obtidos na prova de Formação Específica pelos ingressantes e concluintes de cada curso.

Tabela 5 - Médias de cada curso na Formação Específica de 2008

\begin{tabular}{lccc}
\hline CURSO & SIGLA & Número de alunos & Média de cada Curso \\
\hline Matemática - Formação Específica - Iniciantes & MFEI & 9590 & 25,763126 \\
Matemática - Formação Específica - Concluintes & MFEC & 10347 & 30,648238 \\
Letras - Formação Específica - Iniciantes & LFEI & 17886 & 38,610570 \\
Letras - Formação Específica - Concluintes & LFEC & 22752 & 43,955558 \\
Física- Formação Específica - Iniciantes & FFEI & 3137 & 24,396963 \\
Física - Formação Específica - Concluintes & FFEC & 2343 & 34,064962 \\
Química- Formação Específica - Iniciantes & QFEI & 6719 & 20,496306 \\
Química - Formação Específica - Concluintes & QFEC & 5349 & 27,094979 \\
Biologia- Formação Específica - Iniciantes & BFEI & 15609 & 30,786489 \\
Biologia - Formação Específica - Concluintes & BFEC & 14980 & 37,033819 \\
Pedagogia- Formação Específica - Iniciantes & PFEI & 37473 & 41,153551 \\
Pedagogia - Formação Específica - Concluintes & PFEC & 39949 & 49,657681 \\
História- Formação Específica - Iniciantes & HFEI & 9220 & 33,289062 \\
História - Formação Específica - Concluintes & HFEC & 10529 & 37,538037 \\
Geografia- Formação Específica - Iniciantes & GFEI & 6075 & 32,468961 \\
Geografia - Formação Específica - Concluintes & GFEC & 8179 & 35,746160 \\
\hline
\end{tabular}

Considerando não exequível a comparação entre as provas específicas, verifica-se a diferença entre as médias de concluintes e ingressantes em cada curso, sendo os resultados apresentados na Figura 2. 
Figura 2 - Diferenças entre as médias de pontuação obtidas pelos concluintes e pelos ingressantes na Formação Específica de 2008

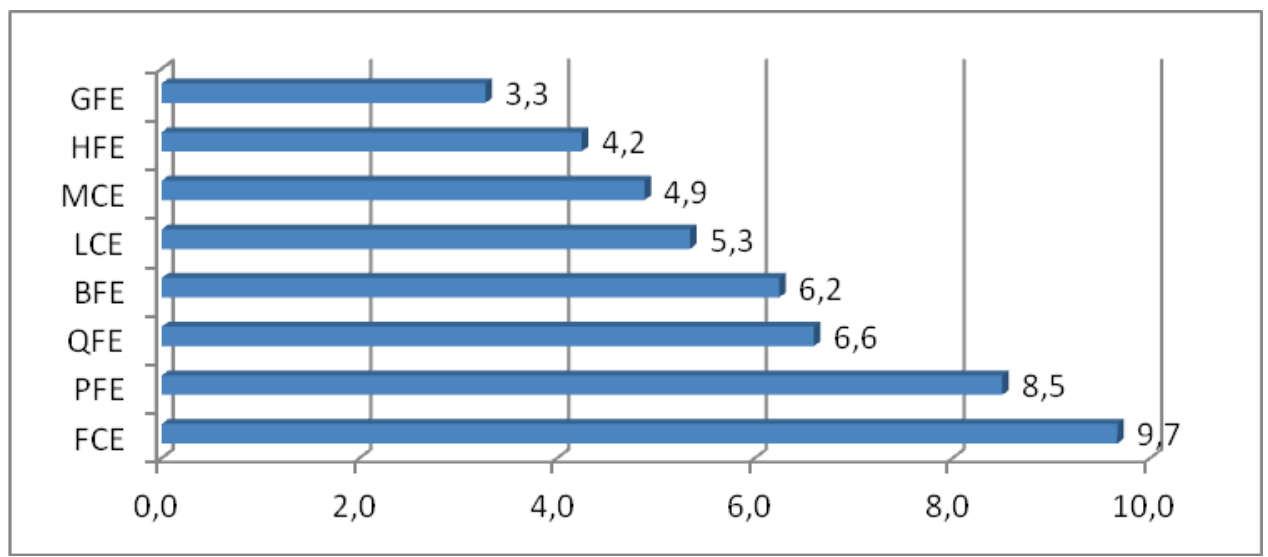

Observa-se o pronunciado crescimento ocorrido nos cursos de Física e Pedagogia, e, em menor grau, em Biologia e Química, indicando que as temáticas apresentadas no exame foram abordadas com pronunciada ênfase ao longo da formação dos estudantes, proporcionando o desenvolvimento conceitual de aspectos específicos da área, cuja compreensão encontrava-se ainda incipiente nos ingressantes. Visando o aprofundamento destas informações foi obtido o aumento ocorrido em termos percentuais a partir do desempenho dos ingressantes. Os resultados estão na Figura 3.

Figura 3 - Aumento no desempenho (em \%) dos concluintes em relação aos ingressantes na Formação Geral e na Formação Específica de 2008

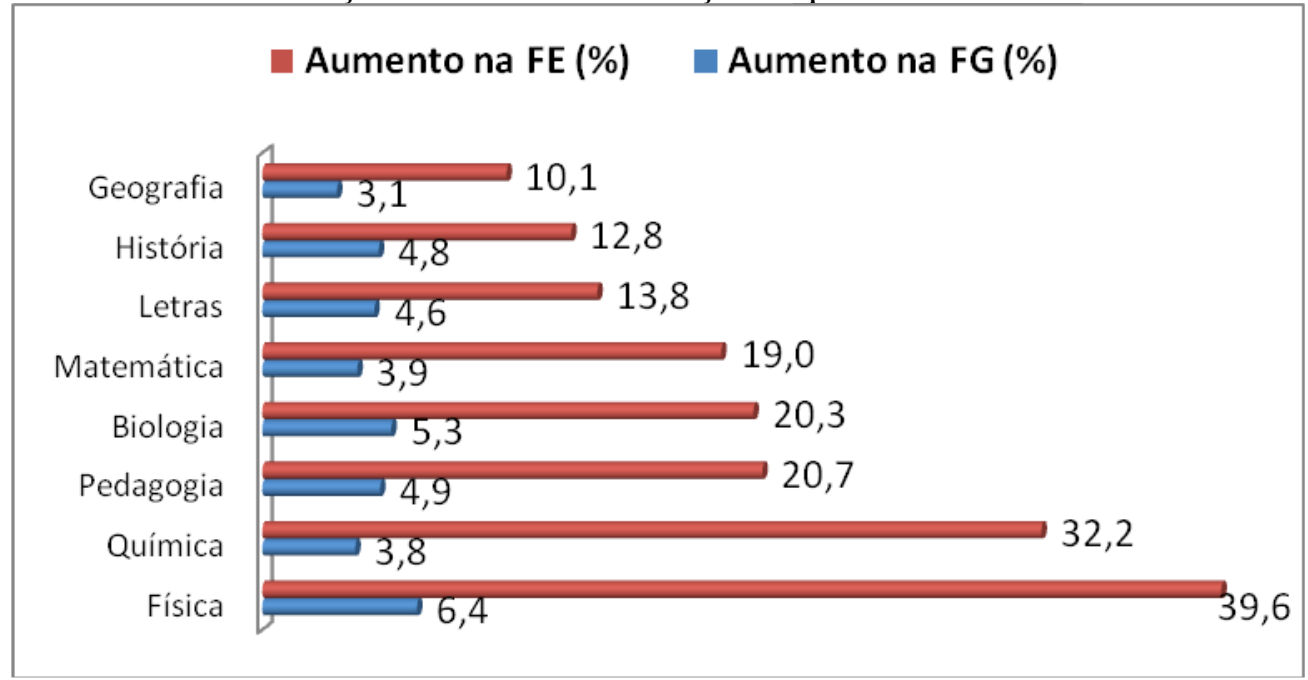

Nos cursos em Ciências houve um aumento mais pronunciado dos ingressantes para os concluintes no âmbito da Formação Específica, resultado da ênfase em tais aspectos durante a formação inicial dos professores. Destacam-se principalmente os dados dos cursos de Química e Física, trabalhando aspectos ao longo dos cursos que não estavam presentes no Ensino Médio e no início dos cursos, tal como apresentados na profundidade em que se encontram no ENADE.

Percebe-se ainda, que no Curso de Física ocorreu o maior aumento percentual, tanto na FG, quanto na FE. Entretanto, o aumento percentual na FG pode ser explicado parcialmente 
pelo reduzido índice obtido pelos ingressantes do presente curso, como pode ser observado na Tabela 4, já que ficou entre as quatro médias mais baixas.

Houve disparidade, no entanto, no momento de compararmos o incremento ocorrido em alguns cursos na FE na FG, indicando uma maior ênfase nas temáticas de formação específica ao longo do curso. Considerando serem as questões de FG iguais para todos os cursos, este aspecto pode se constituir em alerta no sentido de repensar a contextualização das temáticas trabalhadas nos diferentes componentes curriculares de cada licenciatura, na medida da pertinência atribuída a estes aspectos por cada curso. No ano de 2005, os maiores crescimentos na FG ocorreram no curso de Biologia (4,8 pontos), seguido pelos cursos de Química $(3,4$ pontos) e Física $(2,8)$. Portanto, em duas edições consecutivas do ENADE, as diferenças entre os concluintes e os ingressantes foram elevadas nos cursos de Biologia e Física, já para Química este aumento pronunciado ocorreu apenas em 2005.

O desenvolvimento do estudante ao longo do curso é influenciado por múltiplos fatores, sendo a concomitância de estudo e jornada de trabalho um aspecto importante. Dados do ENADE de 2005 apontaram os percentuais de alunos que informaram não trabalhar, sendo sustentados integralmente pela família: Química, Física e Biologia, entre 34\% e 41\%; valores superiores aos mencionados nos demais cursos, tais como Pedagogia, Matemática, Letras, Geografia e História (entre 19 e 29\%). Outro aspecto observado foi a redução destes percentuais ao longo da graduação, quando são comparados ingressantes e concluintes, caracterizando a inserção dos estudantes no mercado de trabalho ao longo de sua trajetória acadêmica e prejudicando o engajamento em atividades de pesquisa e extensão, embora o fato de parte dos estudantes atuarem na docência represente algo relevante para a sua formação.

Analisando diferentes estudos, Gatti e Barreto (2009) apontam que a maioria das disciplinas obrigatórias oferecidas pelos cursos de Ciências Biológicas pelas instituições de ensino superior refere-se aos conhecimentos específicos da área, correspondendo a $64,3 \%$ do total, se constituindo em um percentual elevado quando comparado às demais licenciatura, Os "conhecimentos específicos para a docência" perfaziam 10,4\%. Há, portanto, um pronunciado predomínio de conteúdos disciplinares da área e menor ênfase à docência no referido curso segundo as autoras.

Prosseguem discorrendo sobre o tema indicando que "muito do que os professores sabem, sentem, pensam e a forma como atuam nas escolas tem a ver não apenas com as experiências estritas de escolarização ..., mas com a sua própria experiência de vida e com as formas mais amplas pelas quais eles se inserem na sociedade contemporânea e se relacionam com os bens culturais" (GATTI e BARRETO, 2009, p. 169).

Em relação às atividades desenvolvidas ao longo do curso, os Relatórios Síntese de 2005 apontam que aproximadamente $60 \%$ dos estudantes dos cursos de Química, Física e Matemática afirmaram não ter realizado "nenhuma" atividade denominada "não obrigatória", o que inclui pesquisa, extensão e monitorias. Nos demais cursos, este percentual ficou situado entre 40 e $48 \%$, incluindo o curso de Biologia (42,9\%).

Nesse sentido, as Diretrizes Curriculares Nacionais têm fomentado a ampliação destas ações, inclusive com a inserção das "Atividades Complementares" nas cargas horárias totais dos cursos de graduação do Brasil, buscando que os estudantes desenvolvam atividades de pesquisa e extensão durante a graduação.

Os dados dos Relatórios Síntese do ENADE de 2005 indicaram que o percentual informado de "horas dedicadas por semana aos estudos fora das salas de aula" foi mais elevado, considerando as respostas situadas no intervalo de "6 a 8 horas" nos cursos de Física 
(39,8\% dos estudantes), seguidos dos cursos de Química, História e Matemática (25,9\%; $25,5 \% ; 24,2 \%)$, e Biologia, Geografia, Letras e Pedagogia $(22,1 \% ; 20,4 \% ; 20,4 \% ; 17,5 \%)$.

É muito importante discutirmos a respeito dos fatores que, dentro de uma instituição de ensino superior, podem contribuir para que os estudantes obtenham melhores resultados. Embora a mensuração isolada do desempenho dos alunos se constitua em indicador passível de discussão, segundo Moreira (2011) este dado associado aos fatores que possam interferir nos resultados permite a análise das condições de organização e funcionamento das instituições.

Diaz (2007) assevera que é em relação ao ensino superior que se verifica uma enorme carência de trabalhos para o conhecimento das características institucionais e suas relações com o desempenho dos alunos, mesmo em nível internacional.

As Tabelas 6 e 7 apresentam os dados obtidos com os questionários respondidos pelos alunos que realizaram o ENADE, assim como os dados do Cadastro Docente preenchidos pelas instituições de ensino. Na Tabela 6 encontram-se as informações relacionadas aos equipamentos disponíveis para as atividades.

Tabela 6 - Percentual de instituições nos quais os estudantes indicaram que os equipamentos disponíveis eram suficientes

\begin{tabular}{|c|c|c|c|c|c|}
\hline $\begin{array}{l}\text { \% de alunos } \\
\text { indicando que os } \\
\text { equipamentos eram } \\
\text { suficientes }\end{array}$ & $\begin{array}{c}\text { MATEMÁTICA } \\
\text { (\% de } \\
\text { instituições) }\end{array}$ & $\begin{array}{l}\text { PEDAGOGIA } \\
\text { (\% de } \\
\text { instituições) }\end{array}$ & $\begin{array}{c}\text { FÍSICA } \\
\text { (\% de } \\
\text { instituições) }\end{array}$ & $\begin{array}{l}\text { QUÍMICA } \\
\text { (\% de } \\
\text { instituições) }\end{array}$ & $\begin{array}{l}\text { BIOLOGIA } \\
\text { (\% de } \\
\text { instituições) }\end{array}$ \\
\hline 00,0 a 20 & 4,0 & 3,6 & 2,0 & 5,9 & 14,3 \\
\hline 20,1 a 40 & 12,1 & 14,2 & 20,6 & 17,8 & 10,7 \\
\hline 40,1 a 60 & 20,4 & 18,9 & 22,6 & 18,9 & 16,7 \\
\hline 60,1 a 80 & 26,3 & 32,4 & 38,2 & 27,0 & 23,0 \\
\hline 80,1 a 100 & 37,3 & 30,9 & 16,7 & 30,3 & 35,2 \\
\hline De 60,1 a $100 \%$ & 63,5 & 63,1 & 54,9 & 57,3 & 58,3 \\
\hline
\end{tabular}

Se entendermos como satisfatório o curso, no qual, pelo menos $60 \%$ dos estudantes consideraram os equipamentos disponíveis suficientes, percebe-se que para os três cursos de Ciências os valores são semelhantes, visto que a magnitude encontrada foi semelhante (entre $54,9 \%$ e 58,3\%). Para Pedagogia e Matemática os valores foram levemente superiores, provavelmente pelo fato dos cursos de Ciências possuírem aulas práticas de laboratório mais frequentes e cuja necessidade de material, principalmente de consumo, pode apresentar maiores dificuldades de reposição.

No atual cenário de formulação e implementação de políticas direcionadas para a expansão e a democratização da educação superior, pensar na adequação das instalações físicas e dos recursos de ensino e aprendizagem, assim como nas condições de atuação dos docentes, representa um ponto estratégico para a gestão das instituições de ensino superior (MOREIRA, 2011). Por esta razão, a avaliação dos cursos de graduação realizada pelo MEC atualmente inclui a informação constante da Tabela 6 e a constante da Tabela 7 no Conceito Preliminar de Curso.

Para Moreira (2011) o crescimento do ensino superior privado no país abrangeu não ocorreu de forma homogênea em todas as instituições. Foi possível observar que os efeitos da expansão e da diversificação não foram semelhantes nos diferentes campos do conhecimento. Discorre a autora, que a expansão ocorreu, em um primeiro momento, mais nas áreas de 
Ciências Humanas e Ciências Sociais Aplicadas. Acrescenta Sampaio (2000) que tais áreas requerem um volume menor de investimentos para serem criadas e mantidas, e cujos cursos possuem elevada demanda no mercado. As aulas são ministradas em só um período e com anuidades relativamente mais acessíveis, justamente em razão dos poucos insumos necessários para seu funcionamento. Na Tabela 7 estão os dados relacionados à entrega de planos de ensino pelos professores.

Tabela 7 - Percentual de instituições nos quais os estudantes indicaram que os planos de ensino continham os elementos necessários

\begin{tabular}{|c|c|c|c|c|c|}
\hline $\begin{array}{l}\text { \% de alunos indicando } \\
\text { que os planos de } \\
\text { ensino } \\
\text { adequados }\end{array}$ & $\begin{array}{c}\text { MATEMÁTICA } \\
(\% \text { de } \\
\text { instituições })\end{array}$ & $\begin{array}{l}\text { PEDAGOGIA } \\
(\% \text { de } \\
\text { instituições })\end{array}$ & $\begin{array}{l}\text { FÍSICA } \\
\quad(\% \text { de } \\
\text { instituições })\end{array}$ & $\begin{array}{l}\text { QUÍMICA } \\
(\% \text { de } \\
\text { instituições })\end{array}$ & $\begin{array}{c}\text { BIOLOGIA } \\
(\% \text { de } \\
\text { instituições })\end{array}$ \\
\hline 00,0 a 20 & 3,0 & 0,4 & 4,90 & 3,2 & 3,3 \\
\hline 20,1 a 40 & 17,9 & 5,0 & 38,24 & 25,9 & 19,8 \\
\hline 40,1 a 60 & 36,4 & 27,8 & 31,37 & 37,3 & 32,0 \\
\hline 60,1 a 80 & 26,2 & 41,0 & 20,59 & 21,1 & 30,7 \\
\hline 80,1 a 100 & 16,5 & 25,8 & 4,90 & 12,4 & 14,3 \\
\hline De 60,1 a $100 \%$ & 42,7 & 66,8 & 25,5 & 33,5 & 45,0 \\
\hline
\end{tabular}

Percebe-se que há uma diferença pronunciada entre os valores encontrados para os cursos de Ciências, destacando-se os valores dos cursos de Física, nos quais apenas 25,5\% dos cursos apresentaram percentuais acima de $60 \%$, ao contrário de Pedagogia e Matemática com valores mais elevados, sendo que esta informação se refere à percepção dos estudantes, no sentido da entrega deste material. Salienta-se que neste item houve maior rigor na avaliação, pois foram contabilizadas apenas as respostas dos estudantes a uma das alternativas como satisfatória, diferente da questão envolvendo os equipamentos onde foram consideradas duas alternativas.

Analisando o perfil dos estudantes das licenciaturas através dos resultados do ENADE 2005, Brito (2007) verificou que os alunos fizeram uma apreciação altamente positiva a respeito dos planos de ensino, afirmando que todos ou a maior parte dos professores apresentaram e discutiram planos de ensino com orientações relevantes ou altamente relevantes para a compreensão e acompanhamento do curso.

As tabelas 8, 9 e 10 apresentam os percentuais de Mestres, Doutores e de Regime Parcial e Integral de trabalho.

Tabela 8 - Percentual de instituições em relação ao percentual de mestres no corpo docente

\begin{tabular}{cccccc}
\hline $\begin{array}{l}\text { \% de Mestres no corpo } \\
\text { docente } \\
\text { instituições }\end{array}$ & $\begin{array}{c}\text { MATEMÁTICA } \\
\text { das de } \\
\text { instituições })\end{array}$ & $\begin{array}{c}\text { PEDAGOGIA } \\
(\% \text { de } \\
\text { instituições })\end{array}$ & $\begin{array}{c}\text { FÍSICA } \\
(\% \text { de } \\
\text { instituições })\end{array}$ & $\begin{array}{c}\text { QUÍMICA } \\
(\% \text { de } \\
\text { instituições })\end{array}$ & $\begin{array}{c}\text { BIOLOGIA } \\
(\% \text { de } \\
\text { instituições })\end{array}$ \\
\hline 00,0 a 20 & 12,4 & 10,1 & 0,7 & 2,3 & 2,5 \\
20,1 a 40 & 11,6 & 16,9 & 4,7 & 2,7 & 5,3 \\
40,1 a 60 & 20,0 & 23,9 & 12,0 & 14,5 & 16,2 \\
60,1 a 80 & 26,3 & 25,2 & 32,7 & 25,3 & 30,5 \\
80,1 a 100 & 29,7 & 23,9 & 50,0 & 55,2 & 45,5 \\
\hline De 60,1 a $100 \%$ & $\mathbf{5 5 , 9}$ & $\mathbf{4 9 , 1}$ & $\mathbf{8 2 , 7}$ & $\mathbf{8 0 , 5}$ & $\mathbf{7 6 , 0}$ \\
\hline
\end{tabular}


Tabela 9 - Percentual de instituições em relação ao percentual de doutores no corpo docente

\begin{tabular}{ccccccc}
\hline $\begin{array}{l}\text { \% de Doutores } \\
\text { corpo docente } \\
\text { instituições }\end{array}$ & $\begin{array}{c}\text { no } \\
\text { das }\end{array}$ & $\begin{array}{c}\text { MATEMÁTICA } \\
\text { (\% de } \\
\text { instituições) }\end{array}$ & $\begin{array}{c}\text { PEDAGOGIA } \\
\text { (\% de } \\
\text { instituições) }\end{array}$ & $\begin{array}{c}\text { FÍSICA } \\
\text { (\% de } \\
\text { instituições) }\end{array}$ & $\begin{array}{c}\text { QUÍMICA } \\
\text { (\% de } \\
\text { instituições) }\end{array}$ & $\begin{array}{c}\text { BIOLOGIA } \\
\text { (\% de } \\
\text { instituições) }\end{array}$ \\
\hline 00,0 a 20 & 64,7 & 77,0 & 22,0 & 24,9 & 39,6 \\
20,1 a 40 & 20,2 & 14,3 & 27,3 & 29,0 & 24,2 \\
40,1 a 60 & 9,4 & 4,5 & 24,0 & 22,6 & 22,1 \\
60,1 a 80 & 2,6 & 2,2 & 14,7 & 12,7 & 7,0 \\
80,1 a 100 & 3,0 & 2,0 & 12,0 & 10,9 & 7,0 \\
\hline De 60,1 a $100 \%$ & $\mathbf{5 , 6}$ & $\mathbf{4 , 4}$ & $\mathbf{2 6 , 7}$ & $\mathbf{2 3 , 5}$ & $\mathbf{1 4 , 1}$ \\
\hline
\end{tabular}

Os resultados indicam que os cursos de ciências apresentaram percentuais mais elevados de mestres compondo o seu corpo docente, atingindo mais de $75 \%$ dos cursos possuindo pelo menos $60 \%$ de professores com titulação mínima de Mestre. Em relação aos doutores, os maiores percentuais permanecem sendo nos cursos de ciências, principalmente em Física e Química, embora os valores sejam de baixa magnitude.

No caso dos dados apresentados nas Tabelas 7 e 8 verifica-se que, conforme o Instrumento de Avaliação do Ensino Superior (BRASIL, 2011), os valores médios de Biologia, Química e Física estariam alinhados com o conceito 5 (mais de $75 \%$ de docentes com pelo menos Mestrado) e entre 3 (entre 10 e 20\%) e 4 (entre 20 e 35\%) em relação aos doutores.

Informações obtidas no Geodados da CAPES demonstram que o número de cursos de Mestrado e Doutorado no Brasil cresceu entre os anos de 2000 e 2010 de 131 para 201 nas Ciências Biológicas; de 40 para 58 na Química; de 30 para 52 na Matemática; de 3 para 58 na Área de Ensino de Ciências e Matemática e de 41 para 97 na Educação (BRASIL, 2012a).

O aumento do número de cursos, assim como de titulados se refletiu em maiores percentuais de docentes nos cursos de graduação do Brasil, embora ainda haja um percentual elevado de docentes sem titulação em stricto sensu. Dados do Censo de 2008 indicavam que dos 321.493 docentes atuando na Educação Superior, 35,6\% eram mestres e 24\% doutores, cuja soma contabiliza aproximadamente $60 \%$, valor inferior aos resultados apresentados pelos cursos de Ciências da Tabela 7. Em termos gerais, no ano de 2003 havia 254.153 professores, sendo 35,1\% mestres e 21,4\% doutores (BRASIL, 2009a). A Tabela 10 apresenta os dados referentes ao percentual de professores com regime parcial e integral nos cursos.

Tabela 10 - Percentual de instituições em relação ao percentual com regime parcial ou integral de trabalho no corpo docente

\begin{tabular}{ccccccc}
\hline $\begin{array}{l}\% \\
\text { regime professores parcial } \\
\text { integral de trabalho }\end{array}$ & $\begin{array}{c}\text { ou } \\
\text { instituições })\end{array}$ & $\begin{array}{c}\text { MATEMÁTICA } \\
\text { (\% de }\end{array}$ & $\begin{array}{c}\text { PEDAGOGIA } \\
(\% \text { de } \\
\text { instituições })\end{array}$ & $\begin{array}{c}\text { FÍSICA } \\
(\% \text { de } \\
\text { instituições })\end{array}$ & $\begin{array}{c}\text { QUÍMICA } \\
\text { (\% de } \\
\text { instituições })\end{array}$ & $\begin{array}{c}\text { BIOLOGIA } \\
(\% \text { de } \\
\text { instituições })\end{array}$ \\
\hline 00,0 a 20 & 19,4 & 25,2 & 10,0 & 8,6 & 14,1 \\
20,1 a 40 & 11,0 & 13,7 & 5,3 & 9,5 & 11,5 \\
40,1 a 60 & 12,4 & 16,8 & 8,7 & 15,4 & 11,7 \\
60,1 a 80 & 11,8 & 12,9 & 6,0 & 9,0 & 14,5 \\
80,1 a 100 & 45,3 & 31,4 & 70,0 & 57,5 & 48,2 \\
\hline De 60,1 a $100 \%$ & $\mathbf{5 7 , 1}$ & $\mathbf{4 4 , 3}$ & $\mathbf{7 6 , 0}$ & $\mathbf{6 6 , 5}$ & $\mathbf{6 2 , 7}$ \\
\hline
\end{tabular}


Os resultados demonstram diferenças pronunciadas nos percentuais de docentes com regime parcial ou integral entre os cursos, com destaque para o curso de Física. Este aspecto é de fundamental relevância por apresentar relação direta com a realização de atividades fora da sala de aula. São considerados de tempo integral e parcial, respectivamente, professores com:

\begin{abstract}
"40 horas semanais de trabalho, na mesma instituição, nele reservado o tempo de, pelo menos, 20 horas semanais para estudos, pesquisa, trabalhos de extensão, planejamento e avaliação"... "docente contratado atuando com 12 ou mais horas semanais de trabalho na mesma instituição, reservado pelo menos $25 \%$ do tempo para estudos, planejamento, avaliação e orientação de estudantes” (BRASIL, 2011).
\end{abstract}

Acrescenta-se ainda, que, conforme a legislação para obter conceito 3 o curso precisa ter pelo menos $33 \%$ do corpo docente previsto/efetivo com regime de trabalho de tempo parcial ou integral, (BRASIL, 2007; 2011) valores bem inferiores às médias observadas na Tabela 9.

\title{
6. Conclusão
}

Diante das mudanças ocorridas na formação de professores do Brasil, acompanhadas pela relevância do ensino de ciências na contemporaneidade, a análise dos dados oriundos do Sistema Nacional de Avaliação do Ensino Superior possibilita reflexões relevantes para pesquisadores, gestores e professores. Nesse sentido, a análise dos dados oriundos do ENADE proporciona subsídios para o constante repensar das práticas educativas preconizadas para os cursos de formação de professores de ciências. No presente caso, os dados de 2008 indicaram que os estudantes dos cursos de Biologia e Química obtiveram índices elevados na FG, assim como os estudantes do curso de Letras, tanto nos ingressantes, quanto nos concluintes. Já para o curso de Física as médias foram de baixa magnitude, embora tenha ocorrido a maior diferença entre os concluintes e os ingressantes, assim como no curso de Biologia.

Quando comparados com os dados de 2005, verifica-se que o curso de Biologia se manteve com médias elevadas em relação aos demais para a FG, ao contrário dos cursos de Química e Física, cujo posicionamento diferente do ocorrido em 2008 indica a complexidade intrínseca ao processo de avaliação de informações desta natureza.

Com relação à formação específica, os cursos de Física e Química apresentaram os maiores percentuais de crescimento, comparando concluintes com ingressantes, indicando que muitos dos aspectos presentes no exame são trabalhados durante a graduação, não sendo contemplados no Ensino Médio e início de curso. Biologia apresentou valores intermediários de aumento percentual. No que tange aos equipamentos, a maior parcela dos cursos apresentou resultados positivos na opinião dos alunos. Em relação aos planos de ensino os valores foram inferiores.

Os percentuais de mestres e doutores nos cursos de ciências ficaram acima de outros cursos analisados, embora houvesse um pequeno número de doutores, assim como foi verificado que o percentual de docentes em regime parcial ou integral ficou acima do mínimo exigido pela legislação.

As análises indicaram aspectos relevantes para as reflexões acerca da formação de professores de ciências no Brasil. Estudos posteriores, com a ampliação da base de dados oriundos de novas avaliações padronizadas, podem indicar caminhos promissores para a discussão das peculiaridades inerentes à formação de professores no ensino de ciências e para o acompanhamento do desenvolvimento dos futuros educadores que atuarão no nosso país. 


\section{Referências}

BOPP, M., DAL-FARRA, R. A. (2011). Exame Nacional de Desempenho dos Estudantes (ENADE): questões institucionais. In: MATTOS, A. P. de et al. (orgs). Práticas Educativas e Vivências Pedagógicas no Ensino Superior. Canoas: ULBRA.

BRASIL. (2012a). CAPES. Geodados. Brasília. Disponível em: http://geocapes.capes.gov.br/ geocapesds/\#app $=c 501 \&$ da7a-selectedIndex $=0 \& 5317$-selected Index $=1 \& 82 \mathrm{e} 1$ selectedIndex $=0$. Acesso em 05 de março de 2012.

BRASIL. (2012b). Instituto Nacional de Estudos e Pesquisas Educacionais Anísio Teixeira. Relatórios Síntese dos cursos no ENADE de 2005. Brasília. Disponível em http://portal.inep.gov.br/superior-sinaes-componentes. Acesso em: 08/03/2012.

BRASIL. MEC. (2011). Instituto Nacional de Estudos e Pesquisas Educacionais Anísio Teixeira. Instrumento de Avaliação de Cursos de Graduação presencial e a distância.

BRASIL. MEC. (2009a). Instituto Nacional de Estudos e Pesquisas Educacionais Anísio Teixeira. Resumo técnico do censo da Educação Superior do Brasil de 2008. Brasília.

BRASIL. MEC. (2009b). Instituto Nacional de Estudos e Pesquisas Educacionais Anísio Teixeira. Sinopse do professor. Disponível em: http://portal.inep.gov.br/basica-censoescolar-sinopse-sinopse. Acesso em: 05/08/2011.

BRASIL. MEC. (2009c). Instituto Nacional de Estudos e Pesquisas Educacionais Anísio Teixeira. Sinopse Estatística da Educação Básica. Disponível em: http://portal.inep.gov.br/basica-censo-escolar-sinopse-sinopse. Acesso em: 05/08/2011.

BRASIL. MEC. (2008a). Instituto Nacional de Estudos e Pesquisas Educacionais Anísio Teixeira. Manual do ENADE 2008. Brasília/DF.

BRASIL. MEC. (2008b). Portaria Normativa N. 12, 5 de setembro de 2008. Brasília/DF.

BRASIL. MEC. (2007). Instituto Nacional de Estudos e Pesquisas Educacionais Anísio Teixeira. Portaria normativa $\mathbf{n}^{\mathbf{0}} \mathbf{4 0}$, de 12 de dezembro de 2007.

BRITO, M. R. F. (2007). Perfil, desempenho e razão da opção dos estudantes pelas licenciaturas. Avaliação, v. 12, n. 3, p. 401-443.

DIAZ, M. D. M. (2007). Efetividade no ensino superior Brasileiro: aplicação de modelos multinível à análise dos resultados do exame nacional de cursos. Economia, Brasília, v. 8, n. 1, p. 99-127, jan./abr.

GATTI, B. A., BARRETO, E. S. de SÁ (org.) (2009). Professores do Brasil: impasses e desafios. Brasília: UNESCO.

KRASILCHIK, M., MARANDINO, M. (2004). Ensino de ciências e cidadania. São Paulo: Moderna, 2004.

MOREIRA, M. A. A área de ensino de ciências e matemática na CAPES: panorama 2001/2002 e critérios de qualidade. Rev. Bras. Pesq. Educ. Ciênc., v. 2, n 1, p. 36-59, 2002 . 
MOREIRA, A. M. A. (2011). Fatores institucionais e desempenho acadêmico no ENADE um estudo sobre os cursos de Biologia, Engenharia Civil, História e Pedagogia. In: Simpósio Brasileiro da ANPAE, 25, São Paulo. Disponível em: http://www.anpae.org.br/simposio2011/cdrom2011/PDFs/trabalhosCompletos/comunic acoesRelatos/0045.pdf. Acesso em 27 de março de 2012.

PIMENTA, S. G.; GHEDIN, E. (orgs.). (2005). Professor Reflexivo no Brasil: gênese e crítica de um conceito. $3^{\text {a }}$ Ed. São Paulo: Cortez.

SAMPAIO, H. (2000). O ensino superior no Brasil: o setor privado. São Paulo: Hucitec; FAPESP.

SOUSA, J. V. (2011). Racionalidades e práticas no uso dos resultados do ENADE 2008: o caso dos cursos de licenciatura da Universidade de Brasília. In: Reunião Anual da ANPED, 34, Natal. Disponível em: <http://www.anped11.uerj.br/GT11436\%20int.pdf>. Acesso em 26 mar. 2012.

VENDRAMINI, C. M. M., NOGUEIRA, S. O., LOPES, F. L. (2010). The statistics items in the Brazilian national student performance exam (ENADE). Intern. Assoc. of Statistical Education. Disponível em: http://www.stat.auckland.ac.nz/ iase/publications/icots8/ICOTS8_5B1_VENDRAMINI .pdf. Acesso em março de 2012. 